HOMENS POR VIR:

\title{
REFLEXÕES SOBRE O PROCESSO DE CONSTRUÇÃO DAS MASCULINIDADES NA EDUCAÇÃO INFANTIL' A PARTIR DE JOGOS E BRINCADEIRAS
}

\begin{tabular}{c}
\hline BECOMING MEN: \\
REFLECTIONS ABOUT THE CONSTRUCTION OF MASCULINITIES IN CHILD EDUCATION \\
THROUGH GAMES AND PLAYING \\
HOMBRES POR VIR: \\
REFLEXIONES SOBRE EL PROCESO DE CONSTRUCCIÓN DE LAS MASCULINIDADES EN \\
LA EDUCACIÓN INFANTIL A PARTIR DE JUEGOS Y BROMAS
\end{tabular}

Paulo Melgaço Silva Junior ${ }^{1}$ Maria Vitoria Campos Mamede Maia ${ }^{2}$ Ana Ivenicki ${ }^{3}$

RESUMO: Este artigo aborda modos pelos quais alunos da educação infantil constroem e vivenciam, por meio de jogos e brincadeiras, suas masculinidades. Para tal, apropriando-nos de estudos de gênero, culturais e winnicottianos discutimos como os alunos de uma creche localizada em Duque de Caxias - RJ constroem e revelam, no cotidiano escolar, suas masculinidades. Neste sentido, o objetivo central deste texto é refletir como alguns jogos e brincadeiras na educação infantil interferem diretamente no processo de coconstrução das masculinidades. Os principais instrumentos para a geração destes dados foram a observação do cotidiano escolar, as anotações de conversas informais consideradas significantes feitas por um dos autores e as memórias de ex-alunos, por meio de contatos realizados nas redes sociais. A partir dos resultados obtidos, verificamos que, por meio do planejamento e do desenvolvimento de jogos e brincadeiras na educação infantil, as crianças evidenciaram uma desnaturalização de marcas e visões essencializadas da identidade masculina, contribuindo para problematizar processos hegemônicos de construção de suas masculinidades.

PALAVRAS-CHAVE: Jogos e brincadeiras. Masculinidades. Educação infantil.

ABSTRACT: This article discusses some of the ways in which children's students co-create and experience their masculinities through play and play. To this end, appropriating the study of gender, cultural studies and Winnicottian studies discusses how the students of a day care center located in Duque de Caxias - RJ build and reveal their masculinities in school everyday. In this sense, the central objective of this text is to reflect how some games and games in early childhood education interfere directly in the process of coconstruction of masculinities. The main instruments for generating these data were the observation of daily school life, the register of informal conversations considered significant by one of the authors, and the memories of ex-pupils, as gleaned through their contacts in the social net. Data evidenced that, through careful planning and development of games and plays in child education, the children could denaturalize essentialised imprints and perceptions of masculine identitiy, therefore contributing to problematize hegemonic processes of the construction of their masculinities.

KEYWORDS: Games and playing. Masculinities. Child education.

Submetido em: 22/08/2017 - Aceito em: 03/10/2017 - Publicado em: 21/03/2018

\begin{tabular}{l|c|c|c|c|c|c|} 
(C) Rev. Educ. Perspec. & Viçosa, $M G$ & v.9 & n.1 & p.67-86 & jan./abr. 2018 & eISSN 2178-8359 \\
\hline
\end{tabular}


RESUMÉN: Este artículo analiza algunas formas en que los estudiantes de educación infantil construyen y adquieren, a través de juegos y bromas, su masculinidad. Para ello, a través del estudio de género, de los estudios culturales y de los estudios winnicottianos, se discute cómo los alumnos de una guardería localizada en Duque de Caxias - RJ construyen y revelan, en la vida cotidiana escolar, sus masculinidades. El objetivo es reflejar cómo algunos juegos y bromas en la educación infantil interfieren directamente en el proceso de construcción de las masculinidades. Los principales instrumentos para la generación de estos datos fue la observación de la vida cotidiana escolar y las anotaciones de conversaciones informales, consideradas importantes, hechas por uno de los autores, el registro de conversaciones informales consideradas significativas por uno de los autores, y las memorias de ex alumnos, tal como se obtuvieron a través de sus contactos en la red social. Los datos evidenciaron que, a través de una planificación cuidadosa y el desarrollo de juegos y juegos en la educación infantil, los niños podían desnaturalizar las impresiones y percepciones esencializadas de la identidad masculina, por lo tanto, contribuían a problematizar los procesos hegemónicos de la construcción de sus masculinidades.

PALABRAS CLAVE: Juegos y bromas. Masculinidades. Educación Infantil.

\section{INTRODUÇÃO}

Este trabalho aborda alguns modos pelos quais alunos da educação infantil coconstroem e vivenciam, por meio de jogos e brincadeiras, suas masculinidades. De acordo com Connell (1995; 2000), Badinter (1993) e Moita Lopes (2002; 2006), as masculinidades são construídas com base em projetos de masculinidade hegemônica. Em outras palavras, ressaltamos que pensar em masculinidade hegemônica é pensar em uma versão de algo que foi criado, construído, imaginado, considerado como padrão e disseminado a partir do discurso e que, a cada momento, busca ser consolidado nas performances de masculinidades, apoiadas neste discurso.

A partir do trabalho de docência de um dos autores, analisando as suas anotações e relatórios, escolhemos duas situações cotidianas da creche localizada no $1^{\circ}$ Distrito de Duque de Caxias, como campo de pesquisa, quando o estudo foi desenvolvido, no ano de 2012, e dois depoimentos de alunos relatados ao pesquisador, no ano de 2017. Dessa forma, a metodologia utilizada para o levantamento de dados deste artigo foi uma pesquisa qualitativa, sendo caracterizada com um viés de pesquisa-ação, já que, como dito, um dos autores é docente da instituição aqui citada e relata, em parte, o seu trabalho na mesma.

O objetivo deste trabalho foi analisar como os jogos e as brincadeiras vivenciadas pelos alunos desta creche constroem e revelam, no cotidiano escolar, suas masculinidades, por meio de atividades que os envolviam tanto no intervalo como aquelas propostas na disciplina de ballet. Para complementar as análises, utilizamos depoimentos/reflexões de dois alunos sobre as lembranças vivenciadas no período de cinco anos anteriores ao presente estudo. Para tanto, apropriamo-nos de estudos de Gênero, Culturais e os estudos winnicottianos sobre o brincar e sua importância para realizar a discussão proposta como linha condutora deste artigo.

\begin{tabular}{l|c|c|c|c|c|c} 
(C) Rev. Educ. Perspec. & Viçosa, $M G$ & v.9 & n.1 & p.67-86 & jan./abr. 2018 & eISSN 2178-8359 \\
\hline
\end{tabular}


Defendemos a importância deste estudo, uma vez que a escola constitui um local privilegiado para que meninos e meninas aprendam as possibilidades de serem masculinos e femininos. Serão nessas instituições que as relações de poder entre homens e mulheres, meninos e meninas se darão com grande intensidade, pelo discurso e por práticas de regulação de corpos e desejos. Conforme Moita Lopes (2002, p. 91), "as escolas, por exemplo, determinam em grande parte não somente o que as pessoas fazem como também quem são, serão e podem ser", tendo também a função de "legitimar ou recusar essas identidades, entre outros significados previamente construídos” (MOITA LOPES, 2002, p. 204).

Em termos de estudos culturais, particularmente a vertente multicultural, observamos que autores tais como Ivenicki e Xavier (2015) defendem que essa perspectiva pode ser um caminho mediante o qual a educação valorize a diversidade cultural, de gênero, orientação sexual, raça, etnia e outros marcadores identitários, de modo a promover a superação de preconceitos e possibilitar a formação de futuras gerações abertas à pluralidade. Isto porque a identidade, considerada categoria central na visão dos estudos multiculturais, é percebida como em processo de construção e reconstrução permanente, incluindo as identidades coletivas de gênero, o que traz a possibilidade de professores e educadores trabalharem o currículo em perspectivas desafiadoras de imagens congeladas e essencializadas de gênero.

Para Winnicott (1975), o homem ganha sua condição de humanidade quando consegue sair de um brincar subjetivo, na inter-relação entre o bebê e sua mãe (mãe aqui entendido como um papel de cuidado) para um brincar compartilhado a partir do surgimento do primeiro triângulo existente na vida psíquica do ser humano, que advém da possibilidade de simbolizar (MAIA, 2017). A partir dos processos de projeção e introjeção forma-se a possibilidade de identificação do estado do eu sou (WINNICOTT, 1996). Quando o ser humano consegue perceber que há outro diferente de si mesmo, ele se abre para o brincar. Desta forma, Winnicott (1975) reafirma que somente no brincar o ser humano consegue captar o sentido da vida e do estar vivo. Neste espaço denominado transicional, gesta-se o lugar da criatividade, da cultura, um espaço de manobra quando a vida pede um preço muito alto para que possamos lidar com a chamada realidade. Assim sendo, neste espaço que nem é dentro e nem é fora, aprendemos a lidar com o que seremos e o que somos. Diz-nos Winnicott (1996) que as duas palavras mais difíceis do mundo e mais aterradoras no sentido de darmo-nos conta e que o outro é diferente de mim é o eu sou, neste momento podemos nos diferenciar do outro, mas esse outro igualmente pode existir apesar de mim.

A retaliação surge como real possibilidade de existir. O brincar minimiza esse medo de lidar com o outro e torna o mundo onipotente do bebê em um mundo relacional vivenciado pelo mesmo. O que somos é exatamente fruto desse caminho de construirmos uma alteridade e, assim, uma identidade. O processo é o principal veículo do ser humano em sua capacidade de manter-se em um vir a ser que não se esfacela diante das adversidades. $\mathrm{O}$ brincar propicia ao

\begin{tabular}{l|c|c|c|c|c|c} 
() Rev. Educ. Perspec. & Viçosa, $M G$ & v.9 & n.1 & p.67-86 & jan./abr. 2018 & eISSN 2178-8359 \\
\hline
\end{tabular}


professor abrir uma comunicação não verbal com a criança, gerando um espaço de partilhamento e construções mútuas.

Acreditamos que a relevância do presente estudo ocorra porque, em nossa sociedade, o discurso que dita e reforça as normas preconizadas pela masculinidade hegemônica (CONNELL, 2000) ainda é muito forte e sufoca ou desconsidera diversas outras formas de masculinidades. Sendo assim, possibilitar às crianças, ainda na educação infantil e anos iniciais do ensino fundamental, a participarem e vivenciarem outros discursos, pode contribuir para diminuição da violência de gênero, homofobia e LGBTfobia, infelizmente ainda muito presentes em nossa sociedade. Neste sentido, no espaço escolar, heterossexualidade e masculinidade se enlaçam e transformam-se em um vínculo natural, dado e legitimado. $\mathrm{O}$ trabalho de produção de identidades se torna sistemático, acentuado pela preocupação de introduzir o menino ao mundo masculino hegemônico (CONNELL, 1995; 2000), como o dos esportes, do reconhecimento da agressividade física, ao mesmo tempo em que valoriza sua facilidade para o domínio da racionalidade, enquanto que, com a menina, busca enfatizar a delicadeza e a emoção.

Nesta perspectiva, normalmente, nas turmas de educação infantil, as atividades extracurriculares são divididas claramente por gênero, não sendo permitido mudanças. Determinadas aulas para meninos, outras para meninas. Futebol e capoeira para meninos, ballet para meninas, ilustrando claramente o pensamento de Connell (1995; 2000). Neste caso, não é permitido às crianças experimentarem novos jogos e possibilidades de coconstruírem suas identidades. São negadas possibilidades de participar de jogos e brincadeiras que possam problematizar, descontruir a visão hegemônica.

Devemos destacar que este processo se dá de formas sutis e quase imperceptíveis. Os jogos e as brincadeiras infantis nos mostram claramente como o pensamento hegemônico é reforçado e naturalizado. É no brincar que a criança busca o seu self (eu), usufruindo sua liberdade de criação (WINNICOTT, 1975). Portanto, no brincar há a possibilidade de traduzir, a partir de linguagens simbólicas e sensíveis, experiências não traduzíveis em palavras (MAIA, 2014).

O presente artigo está estruturado da seguinte maneira: no primeiro momento propomos que seja repensado o projeto de construção das sexualidades e das masculinidades. Logo após, desenvolvemos uma discussão sobre o início do processo de construção das masculinidades nas crianças. Os jogos e as brincadeiras que propiciam este caminhar são tematizados na seção seguinte. A Creche, que serviu como lócus para esta pesquisa, as interações cotidianas vivenciadas naquela e os depoimentos dos alunos, são apresentados logo a seguir. Por fim, tecemos nossas considerações finais. 


\section{REFLEXÕES SOBRE MASCULINIDADES}

A categoria gênero, segundo Moita Lopes (2006), pode ser considerada como uma das categorias cruciais para entender as mudanças sociais e culturais da vida contemporânea. Ao mesmo tempo, Butler (2004) nos mostra que entender gênero no contexto global pode nos permitir combater falsas formas de universalismos, principalmente porque, em nossas sociedades, as pessoas apenas se tornam compreensíveis quando se tornam generificadas nos padrões reconhecidos. A mesma autora (BUTLER, 2003, p. 38) define como Gêneros "inteligíveis" "aqueles que, em certo sentido, instituem e mantêm relações de coerência e continuidade entre sexo, gênero, prática sexual e desejo". Nesta perspectiva, a matriz de inteligibilidade presente em nossa sociedade é a matriz da heterossexualidade.

As práticas reguladoras instituem a heterossexualização do desejo e os discursos buscam produzir atributos do masculino/feminino e macho/fêmea. Tudo isso tentando mostrar que a heterossexualidade, além de natural e dada, é a-histórica e universal, tornando-a norma em nossa cultura, estilo de vida e relacionamentos. Contudo, a perspectiva crítica, principalmente feministas, busca mostrar que a heterossexualidade não é simples, ou universal.

Assim, a heterossexualidade se torna compulsória e, nas palavras de Rich`s apud Sullivan (2003), se transforma em uma instituição e adquire um papel central no processo de dominação masculina. Desta forma, esta pode funcionar para reafirmar os valores e as relações patriarcais, criando diversas redes e discursos que buscam assegurar o mito de que a heterossexualidade é natural, e igualmente uma essência.

As masculinidades são construídas e reconstruídas, não podendo ser tomadas como realidades imutáveis e objetivas, estando sempre mudando de acordo com a história e a cultura, bem como estão sujeitas às relações de poder. Então, para ser homem é preciso tornar-se homem (BADINTER, 1993), o que sugere que o caminho para concretizar as regras da masculinidade precisa ser construído e conquistado.

Nesta perspectiva, ainda segundo Badinter (1993, p. 4), a virilidade não é um dom. Ao contrário, deve ser "fabricada - o homem é uma espécie de artefato". Assim, a estrutura patriarcal, instaurada pela ideologia e consolidada por meio do senso comum e pelo poder, cria regras e define o masculino como o ativo e o feminino como passivo, dá destaque para a força masculina em contraste com a delicadeza feminina e produz as masculinidades hegemônicas. Ressaltamos que, numa cultura patriarcal, a diferença é sempre lida em termos hierárquicos, tendo o masculino como polo de autoridade. Então, a diferença se torna diferença/dominação (CONNELL, 1995).

\begin{tabular}{l|c|c|c|c|c|c} 
() Rev. Educ. Perspec. & Viçosa, $M G$ & v.9 & n.1 & p.67-86 & jan./abr. 2018 & eISSN 2178-8359 \\
\hline
\end{tabular}




\section{Não se nasce homem - torna-se homem ${ }^{i i}$}

Badinter (1993), entre outros/as autores/as, nos mostra que o processo de construção da mulher e do homem é demorado, requer investimento e um trabalho sistemático. Neste sentido, os estudos de Winnicott (1975) nos mostram que homens e mulheres nascem com predisposição à bissexualidade. Em outras palavras, existem elementos masculinos e femininos puros em homens e mulheres. Serão estes elementos masculinos e femininos em meninos/homens e meninas/mulheres que constituirão o self.

Winnicott (1975) propõe a dissociação dos elementos puros, no caso do homem o elemento puro feminino (split-off). Este elemento puro estabelece a experiência de ser, uma vez que desde o momento do nascimento acontece a relação com o seio, no sentido união em relação ao objeto/ sujeito. Já em uma perspectiva oposta, o elemento puro masculino é relacionado ao fazer, fato que pressupõe uma relação de separação entre objeto/sujeito. Com isso, a presença do elemento feminino puro destilado em sujeitos do sexo masculino pode conduzir a experiência do ser e se torna a base para autodescoberta e para o sentimento de existir.

No entanto, a formação do self começa antes do nascimento do sujeito. Winnicott (1975) nos apresenta um caso clínico de um homem casado de meia idade que não conseguia terminar seu tratamento. Durante uma determinada seção, o psicanalista pontuou: "estou falando com uma moça" (não se tratava de dúvida da masculinidade do paciente). Logo após veio à tona que sua mãe imaginava uma menina durante a gestação. Assim, ela primeiro viu a menina antes de aceitá-lo como menino. Com isso, o homem teve que se adaptar às ideias da mãe de que seria uma menina. Logo após ele impôs suas defesas no processo de construção como homem, sem, no entanto, se dissociar do elemento feminino que o constituía. Contudo, essa análise é bastante ampla e não pretendemos explorar as possibilidades de dissociação do elemento feminino expelido (split-off) em pacientes masculinos. O que interessa aqui é a constituição dos dois elementos em sujeitos masculinos e que, em momentos futuros, será moldada pela cultura.

Em paralelo ao que foi dito, Louro (2004, p. 15) argumenta que a preocupação em construir e afirmar uma identidade sexual legitimada pela sociedade tem início ainda no útero materno, pois, a partir da "declaração 'é uma menina' ou 'é um menino", desencadeia-se todo um processo de construção da identidade de gênero do sujeito. Assim, baseada nas características físicas e fisiológicas, toda a sociedade, de um modo geral, se une para fazer com que o sexo biológico indicado siga o caminho e as normas convencionais de gênero e de sexualidade, resultando em trabalho sistemático, em um "processo pedagógico contínuo" (LOURO, 2004, p. 16). 
Para tal, são oferecidos diversos subsídios que auxiliarão essa viagem, fazendo com que o sujeito inicie sua caminhada rumo ao processo de construção de sua própria identidade social e sexual. O primeiro subsídio pode ser visto e denotado por roupinhas, móveis e utensílios que a criança usará: azul e verde se for do sexo masculino, rosa e amarelo para o feminino. Nessa jornada, a família constitui o núcleo social em que a criança receberá as primeiras noções sobre o que é ser homem ou mulher. Será nesse núcleo que a criança aprenderá os primeiros significados de como deve se portar para corresponder às normas impostas pela sociedade à qual pertence.

Nesta perspectiva, destacamos que infância e adolescência são os ciclos em que se dão os adestramentos fundamentais para continuar o processo de fabricação de corpos sexuais iniciados com a nomeação do gênero no momento de sua descoberta. Inúmeros acessórios (brinquedos, utensílios e banheiros escolares, vestimentas e cores) são utilizados nessa arte de fazer o corpo, o gênero e o sexo. Todos os acessórios em fronteiras bem desenhadas cotidianamente nas escolas, nas famílias, nas instituições disciplinares. É como se estivessem arquitetonicamente desenhados para que não exista 'desordem' nos gêneros e, consequentemente, tumulto na identidade e desejos sexuais (CAETANO; SILVA JUNIOR; HERNANDEZ, 2014).

No que diz respeito à educação infantil, propriamente dita, Vianna e Finco (2009, p. 272) destacam que este processo pode ser considerado como "um rito de passagem contemporâneo que antecipa a escolarização, por meio da qual se produzem habilidades". Ou seja, uma caminhada para produzir corpos masculinos e femininos que atendam às expectativas das regras sociais. Para tal, as brincadeiras, os brinquedos, os jogos propostos terão papel fundamental neste processo. A partir destas reflexões e cientes de que o masculino é fabricado, na próxima seção discutiremos como os jogos e brincadeiras podem contribuir para a construção do homem de amanhã.

\section{Entre jogos e brincadeiras, a construção do masculino}

O brincar é essencial no processo de construção do self (eu). É no brincar que a criança descobre o mundo à sua maneira e descobre a si mesma, cria consciência de si e de outros. Winnicott (1975) nos mostra que é no brincar que a criança e o adulto liberam sua liberdade de criação, sendo este o momento que se manifesta a sua criatividade. Nesta perspectiva, este indivíduo criativo descobre o seu eu.

O brincar promove a inteligência, produz formas de aprendizado e de interação com os outros e com diversos objetos. Por meio dele, a criança se desenvolve, dando vida aos elementos da brincadeira. Estes elementos são chamados por Winnicott (1975) de elementos transicionais, ou seja, aqueles que levam a criança para outro mundo: do sonho e da fantasia. Neste sentido,

\begin{tabular}{l|c|c|c|c|c|c} 
() Rev. Educ. Perspec. & Viçosa, $M G$ & v.9 & n.1 & p.67-86 & jan./abr. 2018 & eISSN 2178-8359 \\
\hline
\end{tabular}


o brincar abre a possibilidade de criação a partir de um engendramento entre o mundo real e mundo do interno. É a realidade que vai alimentar essa fantasia. Esse espaço do brincar é chamado por Winnicott (1975) de “espaço potencial”. Este permitirá no decorrer do desenvolvimento organizar sua vida, sua realidade e, principalmente, exercitar seus potenciais. É neste espaço que criança estará representando e reconstruindo seus desejos, sonhos, medos e angústias.

No que se diz respeito às crianças da educação infantil, entre 4 e 5 anos, toda sua energia, atividade motora, fantasias não podem ser negligenciadas. É neste sentido que Vasconcelos (2006) e Maia (2014) destacam que a criança brinca porque é inerente à sua dinâmica interna a necessidade de representar a realidade. Assim, o brincar faz parte do processo evolutivo da criança como nos ensinou Piaget (1970) ao destacar as diversas fases desta que vão desde o período sensório-motor até o operatório formal.

O brincar é prazeroso e satisfaz inúmeras necessidades das crianças e seus desejos. Vasconcelos (2006) destaca que na fase dos 5 anos são as necessidades não realizáveis de pronto que impulsionam a criança a brincar de uma forma simbólica. A construção de um mundo imaginário, a partir da possibilidade anterior de ter vivido o estágio do objeto transicional, faz com que desejos possam ser realizados. Dessa forma, libera-se um agir sobre a realidade que nem é totalmente o real factível nem é o mundo subjetivo somente.

Nesta perspectiva, os papéis sociais começam a ser construídos a partir deste brincar sem compromisso com as regras sociais, mas, de certa forma, dentro das mesmas normas. As regras do cotidiano, transmutadas em veracidades e criações próprias, podem ser vivenciadas e internalizadas por meio das brincadeiras, que igualmente colocam em jogo o que é ser homem e o que é ser mulher.

Assim como o brincar, o jogo é cultural e reflete o pensamento social de uma época e de uma civilização. Este mostra a inserção do homem na sociedade. Os jogos já representaram e continuam a representar diversos rituais. Tomamos como exemplo o ritual de passagem, muito comum em diversos grupos sociais. Nestes rituais, o homem precisa mostrar que é homem a partir de jogos, propostos pelo grupo. Estes jogos sustentam o potencial da masculinidade e da sexualidade.

Neste contexto, Aizencang (2005) nos mostra diversas classificações dos jogos a partir de sua estrutura. Para este artigo nos interessa pensar nos jogos de simulacro, ou seja, aqueles jogos que propõem criar uma situação fictícia separada do mundo real e que permitem, ao jogador, criar um personagem e conduzir suas consequências. Aqui, segundo a autora, o prazer consiste em simular outras pessoas, por máscaras e representações dos outros.

\begin{tabular}{l|c|c|c|c|c|c|} 
() Rev. Educ. Perspec. & Viçosa, $M G$ & v.9 & n.1 & p.67-86 & jan./abr. 2018 & eISSN 2178-8359 \\
\hline
\end{tabular}


Como dissemos acima, trabalhamos com a pesquisa de cunho qualitativo. A proposta constituiu em refletir sobre os modos de se constituir como homens a partir da educação infantil. As problematizações aqui apresentadas têm por objetivo visibilizar modelos para posteriormente formular questões que estes moldes colocam. Optamos por esta metodologia pois ela trabalha com o universo de significados, motivos, aspirações, crenças, valores e atitudes, o que corresponde a um espaço mais profundo das relações, dos processos e dos fenômenos que não podem ser reduzidos à operacionalização de variáveis (MINAYO, 2001).

Os dados aqui analisados foram retirados e ressignificados do caderno de notas de Rosimar Silva (SILVA, 2013) que desenvolveu seu trabalho de conclusão de curso apresentado na Faculdade de Educação da Baixada Fluminense da Universidade do Estado do Rio de Janeiro (UERJ), sob a orientação de um dos autores. Ao mesmo tempo, utilizamos as anotações e experiências vivenciadas por também um dos autores enquanto professor de ballet na comunidade estudada. Outro mecanismo utilizado para a geração de dados foram as memórias de dois alunos que vivenciaram este processo e, cinco anos depois, realizaram uma reflexão sobre a experiência.

A Creche Nossa Senhora (nome fictício), localiza-se numa comunidade, próximo ao Centro do município de Duque de Caxias e atende a uma demanda de 150 crianças de 0 a 5 anos de idade, filhos de trabalhadores. O projeto Casa de Iniciação às Artes (CIART) foi criado pela Secretaria Municipal de Educação (SME) de Duque de Caxias em 2000, tendo iniciado oficialmente suas atividades em 2003. No início, pertencia à sala de leitura e, depois, devido ao seu crescimento, passou a funcionar em sala própria na SME. Este projeto durou até o ano de 2012.

A turma que foi objeto desta pesquisa e reflexões é a pré-escola II, constituída por 27 crianças, 15 meninos e 12 meninas com 5 anos de idade. A clientela era composta por moradores da mesma comunidade, sendo as crianças oriundas de uma classe menos favorecida e a maioria filhos/as de mães que são responsáveis pelo sustento do lar. Devemos destacar que a escolha da creche como objeto para a pesquisa se deu pelo fato de um dos autores ser professor de ballet nesta instituição, e trabalhar há 7 anos com turmas mistas (meninos e meninas), conhecendo, assim, algumas interações cotidianas.

Sobre o curso de ballet

A proposta inicial consistia em oferecer aulas de ballet clássico e consciência corporal para os alunos da creche e das escolas da comunidade e funcionar como um projeto social. Lobato $^{\text {iii }}$ foi o professor de ballet deste projeto e defende a ideia de que um projeto deve

\begin{tabular}{l|c|c|c|c|c|c|} 
(C) Rev. Educ. Perspec. & Viçosa, $M G$ & v.9 & n.1 & p.67-86 & jan./abr. 2018 & eISSN 2178-8359 \\
\hline
\end{tabular}


poder oferecer possibilidades de transformação, de crescimento artístico e cultural, além da questão social.

No que diz respeito aos meninos e rapazes da creche, nas aulas de ballet, o professor Lobato foi desenvolvendo um trabalho sistemático de conquistas e discussões, com o objetivo de tentar romper com o preconceito em relação as masculinidades. Ele nunca acreditou nas separações promovidas pelas escolas em que as meninas devem fazer ballet e os rapazes capoeira ou futebol. Desde o início, este professor deixou sua visão muito clara. A Irmã que dirigia a creche aceitou prontamente a proposta: aulas em turmas mistas.

Importante ressaltar que desde o início de sua docência nesta creche, Lobato propôs terminar com a separação "meninos fazem capoeira e meninas ballet". Para tal, todo início de ano, era realizada uma reunião com os pais e mostrado o que é a dança, seu campo de atuação e possibilidade. Discutiam-se, nesse momento, questões de preconceito, destacava-se a importância da atividade, apresentava-se, a eles, uma aula de ballet e se enfatizavam temas como profissão, masculinidades e preconceito.

Nos primeiros anos de trabalho docente, as reuniões foram mais trabalhosas para o professor. Depois, os responsáveis foram conhecendo e acreditando no trabalho desenvolvido, já que muitos tiveram filhos que foram alunos deste professor. Acreditamos que isto se deu devido ao fato de o seu biótipo se distanciar da figura tradicional e imaginada de uma professora/um professor de ballet. Como acontece nas expectativas de papéis sociais, normalmente, quando se pensa em professora de ballet, espera-se uma mulher muito magra de saia rosa, coque e collant ou em professor também magro, de malha apertada. Lobato não correspondia a esse biótipo.

Na escola também se aprende a ser homem: as interações cotidianas

No ano de 2012, nesta creche aconteceram três interações cotidianas que chamaram a atenção, e se tornaram parte do relatório de Lobato neste ano. O primeiro fato aconteceu no dia 10 de outubro, quando os alunos foram brincar de polícia e ladrão; o segundo aconteceu no dia 24 de outubro, quando a professora promoveu uma brincadeira sobre família. Em terceiro, as aulas de ballet serviam como uma possibilidade de desconstruir, principalmente, entre os adultos, pais e familiares e nas próprias crianças, as perspectivas essencializadas de papéis de gênero. Além dessas interações por meio de brincadeiras e jogos, também foram transcritos dois depoimentos de alunos cinco anos depois de terem sidos alunos deste projeto. Interessante notar que essas interações e depoimentos trazem os pontos de discussão que pretendemos neste artigo, quais sejam, os processos de construção das masculinidades por meio de jogos e brincadeiras na educação infantil.

\begin{tabular}{l|c|c|c|c|c|c|} 
() Rev. Educ. Perspec. & Viçosa, $M G$ & v.9 & n.1 & p.67-86 & jan./abr. 2018 & eISSN 2178-8359 \\
\hline
\end{tabular}


Durante a semana, os alunos tinham horas de atividades livres. Eles podiam brincar livremente no pátio. Um grupo de meninos dedicou-se a brincar de polícia e ladrão. O que chamou a atenção de Lobato foi o fato de a maioria querer ser ladrão. De um grupo de 9 meninos, apenas dois, K. e D., quiseram ser policiais, os demais queriam ser ladrões. Quando estavam procurando as armas, M. disse que "as armas dos bandidos teriam que ser maiores". Quando a professora percebeu a construção das armas, interrompeu a brincadeira e sugeriu que brincassem de outra coisa. Imediatamente, os alunos resolveram brincar de "pega". Só que os policiais pegavam e prendiam os bandidos. Foi um corre-corre, muito agarra-agarra, chegando à violência. A brincadeira só terminou quando $\mathrm{M}$. deu uma mordida e um soco em D. para mostrar que era mais forte que o colega (CADERNO DE NOTAS, 10 out. 2012).

Este relato remete diretamente ao aspecto do jogo e da brincadeira como forma de representação da cultura advinda da experiência desses alunos nesta comunidade. A creche está localizada em uma comunidade não pacificada, que recebe diversos integrantes de outras comunidades pacificadas. Apesar da pouca idade, este jogo de polícia e ladrão faz parte do ritual de muitos destes jovens para serem considerados pertencentes ao local em que vivem e convivem.

Assim, ao refletir uma realidade, nós temos o jogo como simulacro ou como faz de conta, no qual os meninos criam uma situação fictícia, onde encenam aspectos da realidade. Neste contexto, o jogo possui relação direta com a forma de vida de algumas pessoas daquele grupo social. É relevante destacar a fala do aluno M. que, ao defender o poder da arma dos bandidos, talvez estivesse revivendo sua própria história: seu pai está preso.

O prazer foi outra característica da brincadeira e do jogo presente nesta atividade. Além disto, as regras foram previamente acertadas e acordadas entre todos os participantes. $\mathrm{O}$ final do jogo foi marcado pela professora que percebeu o perigo de brincadeiras que representam uma realidade de violência que todos querem mudar. Com a interrupção desta primeira brincadeira, surge uma nova forma de jogo, com características diferentes, agora sem armas, mas de "pega", que só teve fim quando um dos membros se machucou. Interessante pensarmos que o "pega", sem armas, é um espaço lúdico até o momento que o bater e o machucar acontecem. Essa violência, ao irromper o espaço lúdico, o anula, e a brincadeira vira choro, raiva, outras coisas que não são comportadas nesse espaço.

No que se diz respeito ao jogo e à brincadeira relacionados ao processo de construção das masculinidades, aqui presenciamos as questões relativas à masculinidade como pertencimento a um grupo (CONNELL, 1995; MOITA LOPES, 2002). Em outras palavras,

\begin{tabular}{l|c|c|c|c|c|c|}
\hline (C) Rev. Educ. Perspec. & Viçosa, $M G$ & v.9 & n.1 & p.67-86 & jan./abr. 2018 & eISSN 2178-8359 \\
\hline
\end{tabular}


aquela brincadeira era, para o grupo de meninos, a demonstração de força, a presença da violência e, apesar da proximidade física pelo agarra-agarra, pouca ou nenhuma demonstração de carinho, podendo ser por nós percebidas as características dos jogos que constroem o homem, jogos de luta, resistência e não afetividade. Com esta brincadeira, meninos estão aprendendo a se tornarem homens (BADINTER, 1993) e construindo suas identidades e as relações com o mundo que estão inseridos, de forma a associar a masculinidade com a violência, com a assertividade por meio da agressividade, relações estas que, naturalizadas, acabam por reforçar a identidade masculina congelada em termos hegemônicos. Ao subverter a brincadeira inicial, o docente é central na intervenção, propiciando um repensar sobre a identidade masculina. Entretanto, ao desconsiderar a riqueza e a pluralidade das culturas infantis (IVENICKI; XAVIER, 2015), no caso das brincadeiras de polícia e ladrão, observam-se fragilidades, que poderiam ser superadas uma vez que fossem discutidas e trabalhadas a partir do contexto dessas crianças. De qualquer modo, tal interação evidencia o potencial de desarticular a naturalização da articulação masculinoagressor-violento, ressignificando a identidade masculina no contexto escolar, e contribuindo para desafiar a ordem imposta dos gêneros e promover um "tumulto" na identidade em tela (CAETANO; SILVA JUNIOR; HERNANDEZ, 2014).

\section{A segunda interação - dia 24 de outubro de 2012}

Logo no início da manhã, após as atividades de rotina, a professora trabalhou com o tema família. Para isso, ela apresentou diversos personagens de histórias que a turma já conhecia, mostrando vários modelos de família. Perguntou para os alunos sobre as famílias deles e cada um falou sobre a sua. A partir daquele momento, pediu para que os alunos desenhassem uma família que poderia ser, ou não, a sua. Mesmo após muitos alunos terem falado que moravam com tios ou avós, a maioria desenhou o modelo convencional: pai, mãe e um ou dois filhos. Antes do recreio, a professora levou os alunos para a sala de linguagem e propôs que eles brincassem de família. Cada grupo se formou à vontade, sendo que alguns alunos começaram a brincar e logo se desinteressaram da proposta. Porém, uma família me chamou muito atenção: ela era formada pelos alunos F. (pai), R. (mãe), N., L. e P. (filhos). O aluno F. cuidava da casa, mandava os filhos tomarem banho e ainda fazia a comida. A professora até brincou que F. era o único aluno que brincava desta maneira e com aquela concentração (CADERNO DE NOTAS, 24 out. 2012).

Mais uma vez, temos o jogo e brincadeira como simulacro, como faz de conta. Aqui, os participantes imitam situações de pessoas adultas, fingem serem pais e mães. O prazer está em simular esta situação. Diferente da primeira proposta, que havia sido combinada pelo grupo, o início do jogo foi proposto pela professora e talvez, por isso mesmo, não tenha tido a aceitação de toda a turma. Alguns alunos e alunas logo se dispersaram. Também deve ser levada em consideração a fala da professora de que "o aluno F. era o único que brincava desta

\begin{tabular}{l|c|c|c|c|c|c} 
(c) Rev. Educ. Perspec. & Viçosa, $M G$ & v.9 & n.1 & p.67-86 & jan./abr. 2018 & eISSN 2178-8359 \\
\hline
\end{tabular}


maneira". Este aluno é um dos poucos do grupo que mora com a família em modelo tradicional: pai, mãe e filhos. Em sua casa, a mãe é auxiliar de enfermagem e faz plantões e o pai assume as rotinas da casa como: cuidar da casa, levar filhos à escola, ir às reuniões. Neste sentido, por meio da brincadeira, a criança está reproduzindo as atividades diárias do pai. É o modelo de homem que ela tem em casa.

Torna-se importante percebermos que, como no caso anterior, a relação do menino com o pai (ou com aquele que porventura assuma este lugar) terá importante papel no modo como ele desenvolverá as representações simbólicas do masculino. Assim, tivemos acesso a dois processos de construção de jogos e brincadeiras, de M. e de F., nos quais os pais de ambos ofereceram os caminhos para a compreensão da masculinidade. Como a brincadeira reconstrói o mundo real por meio do mundo imaginário, a presença do pai vai influenciar diretamente na aquisição da masculinidade.

É relevante destacar que, no caso do aluno F., esse modelo de masculinidade foge às regras da masculinidade hegemônica. Em outras palavras, ao invés de demonstrar força e virilidade, ele demonstra carinho, atenção. O que aparece aqui é o ser, talvez a partir da influência do elemento feminino (WINNICOTT, 1975). Contudo, mais uma vez, este caso nos mostra que a virilidade é forjada, construída e vigiada. Assim, um menino realizando brincadeiras que não estão diretamente relacionadas às expectativas de papel social chama a atenção dos adultos e, principalmente, da professora, que, nas palavras de Moita Lopes (2002), estão em constante guarda para que os alunos e alunas sigam as normas de gênero, onde masculinidade e heterossexualidade se confundem.

Tal episódio mostra, portanto, por um lado, o potencial das brincadeiras e jogos para a desconstrução do papel identitário essencializado, no foco do presente artigo sendo a identidade masculina, que pode ser desenvolvida de forma dissociada da agressividade e violência e incorporar elementos relacionados ao cuidar, ao emocionar, ao fragilizar, tumultuando a visão essencializada do "ser homem". Entretanto, de outro lado, mais uma vez, mostra a importância de que docentes possam adquirir formação continuada multiculturalmente orientada, de modo a promoverem o diálogo com as culturas plurais (IVENICKI; XAVIER, 2015). Tal perspectiva poderia prover a docente em questão com elementos que pudessem contribuir para que ela aproveitasse a situação retratada por $\mathrm{F}$. de forma positiva, incentivadora do desafio aos preconceitos com relação à identidade masculina que desafia congelamentos hegemônicos, o que não ocorreu na situação aqui retratada.

\section{A terceira interação - meninos fazem aula de ballet}

A terceira interação parte das reflexões advindas da constatação daquilo que a comunidade na qual a creche Nossa Senhora está inserida fez: "os meninos fazem aulas de ballet".

\begin{tabular}{l|c|c|c|c|c|c} 
(C) Rev. Educ. Perspec. & Viçosa, $M G$ & v.9 & n.1 & p.67-86 & jan./abr. 2018 & eISSN 2178-8359 \\
\hline
\end{tabular}


O trabalho de ressignificação que Lobato fez em suas aulas marcou significativamente a forma como os meninos, e a comunidade da Creche, viram meninos fazendo aula de ballet. Ao invés de exercícios como pé de bailarina e bruxa, andar de salto alto, braços da fada e, assim por diante, o referido professor trouxe para as aulas: pé do palhaço, as embaixadinhas do jogador e braços de bola (bola cheia e murcha). Assim, a partir dos jogos e brincadeiras, o ballet era reconstruído pelos alunos que participavam das aulas, não havendo questões de se apresentarem como bailarinos no espetáculo anual da creche. O que de mais importante aconteceu neste processo de meninos fazerem ballet foi a incorporação de um ideário de masculinidade que não denegria uma arte: eles são capazes de discutir com todos, até hoje em dia, que fazer ballet não muda o fato de ser homem.

Uma das recordações mais marcantes deste trabalho aconteceu no dia em que Lobato foi procurado por um pai ${ }^{\text {iv }}$ que queria conhecê-lo, porque quando falou para o filho que homem não fazia ballet, o filho, K. (5 anos) retrucou dizendo que não tinha nada a ver e mostrou os exercícios de jogador, de imitação de animais que eles faziam. Em suma, o pai disse que só deixou o filho fazer ballet depois que assistiu à apresentação e viu que Lobato não parecia aqueles professores de ballet que ele conhecia.

O que nos chama a atenção nesta terceira interação são as questões de gênero e a necessidade de sua inteligibilidade. Neste aspecto, o sexo biológico determina o gênero que, por sua vez, determina as expectativas dos papéis sociais. Com isso, o ballet foi feito para mulher e para homossexuais. Meninos que estão sendo construídos como masculinos e heterossexuais não podem fazer ballet. A própria expectativa da figura do professor/professora determina quem deve ou não participar das aulas.

Neste momento, a figura do professor contribuiu para romper com as questões relativas às expectativas de gênero. Ao mesmo tempo, os jogos e brincadeiras propostas chamaram a atenção dos meninos que se abriram à participação e à própria discussão do processo de construção das masculinidades. Para tal, os jogos foram ressignificados, a proposta do faz de conta continuou a acontecer, porém, foram utilizados personagens do mundo masculino, possibilitando a criação de novos mundos de sonhos e fantasias.

O trabalho que aqui trazemos de jogos e brincadeiras podem, conforme argumentamos, ressignificar e auxiliar na construção de masculinidades. Tal perspectiva foi reafirmada com o depoimento de dois alunos que participaram das atividades em 2012 e que foram alunos de Lobato. Estes depoimentos foram colhidos, em 2017, quando o professor escreveu para os alunos utilizando o facebook. Esses dois alunos já estão na adolescência, e, em suas falas, reafirmam o quanto a experiência de ser um menino fazendo ballet marcou e mudou sua percepção de gênero masculino.

\begin{tabular}{l|l|l|l|l|l|l} 
(ㄱ) Rev. Educ. Perspec. & Viçosa, $M G$ & v.9 & n.1 & p.67-86 & jan./abr. 2018 & eISSN 2178-8359 \\
\hline
\end{tabular}


Depoimento do aluno 1:

Tudo começou quando tinha 5 ou 6 anos, era de creche e foi lá que conheci o ballet. Foram momentos muito bons, como os ensaios, os desfiles, os passeios e as apresentações. Os ensaios eram ótimos graças ao nosso instrutor/professor Lobato. Os passeios, nem diga kkkk. As apresentações, davam um frio na barriga, mas era ótimo ver aquele público aplaudindo as nossas danças. Sei que não estou mais fazendo ballet, por alguns motivos, mas desde quando eu saí percebi que muitas crianças e jovens estavam procurando lugares que ensinam este tipo de dança.

Depoimento do aluno 2:

\begin{abstract}
Meus tios e primos diziam que ballet não era para homem. Meu pai foi até assistir uma aula depois falou que não viu nada de mais na aula, falou que a gente fazia mais alongamento que na capoeira. Outra coisa que lembro dos ensaios é que os passos tinham muita coisa de futebol, de voley, de corrida. Eu fiz ballet uns 4 anos, enquanto estava na creche e até o $3^{\circ}$ ano. Depois parei. Hoje eu lembro de como o ballet ensinou a cuidar das meninas, oferecer a mão, fazer cumprimentos, ser gentil com elas. Eu tenho 15 anos, estou no ensino médio, guardo muitas lembranças daquele tempo, fui ao Theatro Municipal, conheci artistas, tinha muitos passeios e apresentações. Com certeza aprendemos a ser educados, a nos comportar no meio das pessoas adultas.
\end{abstract}

A fala do aluno 2 destaca como a família desenha a viagem que o menino deve seguir para se construir como homem (LOURO, 2004). Ao afirmar que ballet não é para homem, a família demonstra a preocupação de que o garoto siga os caminhos para se tornar homem (BADINTER 1993), revelando como esta vigia a masculinidade e a heterossexualidade (MOITA LOPES 2002). Ao mesmo tempo nos mostra que fazer ballet não se enquadra dentro do projeto de masculinidade proposto pela família (BADINTER, 1993; MOITA LOPES, 2002)

As lembranças, tanto do aluno 1 como a do aluno 2 sobre as atividades trabalhadas em aula de ballet, mostram a relevância dos jogos (AIZENCANG, 2005), da ressignificação das atividades para favorecer o brincar (AIZENCANG, 2005; VASCONCELOS, 2006; MAIA, 2014; 2017; VIANNA; FINCO, 2009), contribuindo, assim, para construção do masculino (WINNICOTT, 1975). Destacamos que a ressignificação da movimentação dos exercícios, assim como, as brincadeiras em sala de aula, contribuíram para a representação da realidade das crianças (VASCONCELOS, 2006), fato que marcou a vida dos jovens.

A partir da fala do aluno 2, defendemos que as aulas de ballet podem ter contribuído para a conscientização dos meninos sobre as questões de gênero, principalmente no que diz respeito ao cuidado com a mulher. O brincar permite desenvolver a consciência de si e do outro e, no depoimento de F., percebemos essa construção e desenvolvimento.

O depoimento do aluno 2 ressalta o cuidado com o outro, com as meninas. Assim, defendemos a importância da brincadeira para introduzir os meninos nas relações/discussões

\begin{tabular}{l|c|c|c|c|c|c} 
() Rev. Educ. Perspec. & Viçosa, $M G$ & v.9 & n.1 & p.67-86 & jan./abr. 2018 & eISSN 2178-8359 \\
\hline
\end{tabular}


de gênero, de modo que, conforme Ivenicki e Xavier (2015), possam tornar-se adultos valorizadores da diversidade e desafiadores de preconceitos e intolerâncias com relação a identidades de gênero e outras.

Como observação, verificamos a contribuição dos dados das fontes analisadas para os objetivos do artigo, no sentido de argumentar pela possibilidade da escola em contribuir para ressignificar modelos de construção identitária, com foco na masculinidade. De fato, a partir dos estudos de gênero e winnicottianos, verificamos que, sem dúvida, há uma relação entre os dados provenientes das diferentes fontes citadas. Um aspecto que se evidencia pelas três cenas narradas é a centralidade da figura do professor intervindo nas brincadeiras das criança, fato este que, no caso da aula de ballet, demonstrou potencialidades na desconstrução da identidade masculina hegemônica mas que, nos episódios relativos ao papel dos membros masculinos da família e àquele relacionado à polícia na comunidade, deixaram a desejar, do ponto de vista multicultural, uma vez que houve fragilidade ao desconsiderar a riqueza e a pluralidade das culturas infantis.

Formação continuada docente na perspectiva multicultural e desconstrutora de estereótipos e essencializações identitárias pode, nesta visão, auxiliar docentes em serviço a detectarem os potenciais intrínsecos às brincadeiras infantis e utilizarem as mesmas em perspectivas transformadoras, rumo a uma sociedade mais justa e igualitária.

\section{CONSIDERAÇÕES FINAIS}

A questão que esteve implícita ao longo deste estudo foi como os jogos e as brincadeiras contribuem para a construção das masculinidades de alunos da educação infantil de uma creche na periferia de Duque de Caxias - RJ. Pudemos verificar que, nesta faixa etária, os jogos e brincadeiras de faz de conta simulam situações reais, nas quais, por meio de personagens fictícios, as crianças criam um mundo imaginário sustentado por elementos reais. Os depoimentos revelaram como as brincadeiras ficaram marcadas na memória de jovens que vivenciaram este momento.

No que se diz respeito ao processo de construção das masculinidades, o jogo/brincadeira escolhido pelo grupo de meninos trouxe à tona a violência e força inerentes ao masculino, ao heterossexual. Contudo, o fato de o menino apresentar um cuidado com os filhos, casa e família mostra que os jogos e as brincadeiras podem ajudar a pensar em novas possibilidades de reinvenção das masculinidades. Neste sentido, as brincadeiras mostraram que servem/ou são utilizadas como simulacro da realidade vivenciada a partir dos momentos em que coloca em jogo a imaginação e o simbolismo. Exatamente por ser culturalmente determinada, a brincadeira e os jogos muitas vezes reproduzem um projeto de masculinidade, no caso deste

\begin{tabular}{l|c|c|c|c|c|c} 
(C) Rev. Educ. Perspec. & Viçosa, $M G$ & v.9 & n.1 & p.67-86 & jan./abr. 2018 & eISSN 2178-8359 \\
\hline
\end{tabular}


artigo, podendo reforçar o pensamento da heterossexualidade compulsória, cabendo ao docente a possibilidade de ressignificação das identidades hegemônicas, por meio de intervenções que possam construir sobre a diversidade das culturas infantis e propiciar o aproveitamento das brincadeiras de forma a desconstruir estereótipos e preconceitos ligados à essencialização das identidades, incluindo as de gênero e, mais especificamente, as masculinidades - foco do presente artigo.

Com outro olhar, sabemos que o espaço do brincar, em que o jogo e a brincadeira habitam como formas de expressão simbólica, possibilita ressignificações. Neste espaço nada é cobrado no sentido do ser ou não real, é tácito que o dia a dia fica suspenso no tempo e no espaço enquanto se brinca. O real se faz presente, é matéria prima de construções simbólicas, mas este se mescla com a fantasia e com o mundo interno de cada um de nós. Assim sendo, a introdução de meninos nas aulas de ballet, a ressignificação dos exercícios convencionais desta arte, permitiram a ampliação das discussões sobre as expectativas dos papéis sociais e gênero, ampliando as fronteiras das discussões sobre masculinidades. Ao introduzir o menino em outros projetos de brincar, em outras atividades (no caso não convencionais para meninos), estaremos provocando discussões de gênero na educação infantil. Com isso, podemos estar desconstruindo visões essencializadas e, principalmente, introduzindo os homens de amanhã nas políticas de gênero e de justiça e igualdade social entre outros e mulheres. Em outras palavras, acreditamos que estaremos mostrando aos meninos a necessidade do respeito e cuidado para com as mulheres.

No entanto, é necessário compreender que essas observações e pesquisa aconteceram em um contexto específico de interação entre meninos. Em outro contexto, estes meninos podem jogar, brincar e construir o seu self de outra maneira. Existe, também, a possibilidade de os meninos participarem de outras experiências de vidas e, então, certamente, haver a possibilidade de eles reinventarem os seus discursos e as suas masculinidades.

\section{REFERÊNCIAS}

AIZENCANG, Noemí. Jugar, aprender y enseñar: relaciones que potencian los aprendizajes escolares. Buenos Aires: Manatial, 2005.

BADINTER, Elisabeth. XY: sobre a identidade masculina. Rio de Janeiro: Nova Fronteira, 1993.

BUTLER, Judith. Problemas de gênero: feminismo e subversão da identidade. Rio de Janeiro: Civilização Brasileira, 2003.

BUTLER, Judith. Undoing gender. New York: Routledge, 2004.

\begin{tabular}{l|c|c|c|c|c|c|} 
() Rev. Educ. Perspec. & Viçosa, $M G$ & v.9 & n.1 & p.67-86 & jan./abr. 2018 & eISSN 2178-8359 \\
\hline
\end{tabular}


CAETANO, Marcio Rodrigo Vale; SILVA JÚNIOR, Paulo Melgaço da; HERNANDEZ, Jimena de Garay. Ninguém nasce homem, torna-se homem: as masculinidades no corpo e o corpo nas práticas curriculares das masculinidades. Revista Periódicus, Salvador, v. 1, n. 2, p. 8-18, nov. 2014.

CONNELL, Robert William. Políticas de masculinidade. Educação e Realidade, Porto Alegre, v. 20, n. 2, p. 185-206, jul./dez. 1995.

CONNELL, Robert William. The men and the boys. Berkeley: The University of California Press, 2000.

IVENICKI, Ana; XAVIER, Giseli Pereli de Moura. Currículo multicultural e desafio a fronteiras de exclusão: reflexões e experiências de construção docente coletiva. In: NASCIMENTO, Adir Casaro; BACKES, José Licínio (Orgs.) Inter/multiculturalidade, relações étnico-culturais e fronteiras da exclusão. Campinas: Mercado das Letras, p. 195$210,2015$.

LOURO, Guacira Lopes. Um corpo estranho: ensaios sobre sexualidade e teoria queer. Belo Horizonte: Autêntica, 2004.

MAIA, Maria Vitória Campos Mamede. Criar e brincar: o lúdico no processo de ensino e aprendizagem. Rio de Janeiro: WAK, 2014.

MAIA, Maria Vitória Campos Mamede. "Rios sem discurso": a agressividade da infância na contemporaneidade. Alemanha: Novas Edições Acadêmicas, 2017.

MINAYO, Maria Cecília de Souza (Org.). Pesquisa social: teoria, método e criatividade. 18 ed. Petrópolis: Vozes, 2001.

MOITA LOPES, Luiz Paulo da. Identidades fragmentadas: a construção discursiva de raça, gênero e sexualidade em sala de aula. Campinas: Mercado das Letras, 2002.

MOITA LOPES, Luiz Paulo da. On being white, heterosexual and male at school: multiple positionings in oral narratives. In: SCHIFFRIN, Deborah; FINA, Anna de; BAMBERG, Michael. Identity and discourse. Oxford: Oxford University Press, 2006.

PIAGET, Jean. A construção do real na criança. Rio de Janeiro: Zahar, 1970.

SILVA, Rosimar Ramos da Silva e. A escola é lugar de brincar? Reflexões sobre a importância do lúdico na educação infantil. Monografia (Graduação em Pedagogia) Faculdade de Educação da Baixada Fluminense, Universidade do Estado do Rio de Janeiro, Duque de Caxias, 2013.

SULLIVAN, Nikki. A critical introduction to queer theory. Nova York: New York University Press, 2003.

\begin{tabular}{l|c|c|c|c|c|c|} 
(C) Rev. Educ. Perspec. & Viçosa, $M G$ & v.9 & n.1 & p.67-86 & jan./abr. 2018 & eISSN 2178-8359 \\
\hline
\end{tabular}


VASCONCELOS, Mário Sérgio. Ousar brincar. In: ARANTES, Valéria Amorim. Humor e alegria na educação. São Paulo: Summus, 2006.

VIANNA, Claudia; FINCO, Daniela. Meninas e meninos na educação infantil: uma questão de gênero e poder. Cadernos Pagu, Campinas, n. 33, p. 265-283, dez. 2009.

WINNICOTT, Donald Woods. O brincar e a realidade. São Paulo: Imago, 1975.

WINNICOTT, Donald Woods. Tudo começa em casa. São Paulo: Martins Fontes, 1996.

\section{NOTAS}

\footnotetext{
${ }^{i}$ Cientes que masculinidades e feminilidades são complementares, neste texto optamos por discutir apenas o processo de construção das masculinidades heterossexuais por se tratar da norma, ou seja, aqui propusemos problematizar e questionar a visão tida como natural.

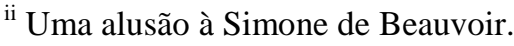

iii Todos os nomes citados são fictícios.

iv $\mathrm{O}$ pai em questão não morava com a família, assim não havia acompanhado as reuniões iniciais com o professor.
}

\section{SOBRE OS AUTORES}

${ }^{1}$ Paulo Melgaço Silva Junior: Pós doutorando em Educação e Doutor em educação pela Universidade Federal do Rio de Janeiro - UFRJ. Professor da Rede pública do Estado do Rio de Janeiro. E-mail: pmelgaco@uol.com.br - ORCID: http://orcid.org/0000-0002-4301-9305

${ }^{2}$ Maria Vitoria Campos Mamede Maia: Professora Associada da Faculdade de Educação da Universidade Federal do Rio de Janeiro. Coordenadora do Grupo de Pesquisa LUPEA-PPGE. Email: mariavitoriamaia@gmail.com - ORCID: http://orcid.org/0000-0002-9697-8243

${ }^{3}$ Ana Ivenicki: Professora Titular da Faculdade de Educação da Universidade Federal do Rio de Janeiro. Pesquisadora do CNPq. E-mail: aivenicki@gmail.com - ORCID: http://orcid.org/0000-00027315-5500 